\title{
The Effect of Anomia on Ethnocentric Tendencies: A Study Among Small Businesses in Two Island Microstates
}

Albent Caruana

\begin{abstract}
ABSTRAC C. Globalisation and related liberalisalion have scen coummes pursue policies that open up domestic markets. Many small businesses that were previously offered domestic protection in the form of ariffs and quotas against imported goods are facing increasingly competilive domestic market conditions. In the context of these changes, this paper focuses on small business, mamagers in the two microstates of Malta and Singapore to determine their levels of anomia and consider ifs elfect on elhnocentrism. Moreover, while elhnocentrism has in the past heen lonked at from a consumer perspective, lhis study looks at ethnocentric tendencies among small business manigers. Data are collected from this group via samples in each of the two countries. Results indicate that anomia is an ancectent varable to ethnocentric tendencies among small business managers. Implications for theory and policy development are considered, limitations are noted and directions for future reseatch are indicalled. IAmicle copies avaluble for a fee from The Haventh Document Delivery Service: 1-800-HAWORTH. E-mail address: <docdelivery@hawenthpress.com> Website: <harp://Www. Han'orlhPress.com> (0) 2005 by The Hawonh Press, hic. All nights reserved. I
\end{abstract}

Abert Cartuna is Associate Professor, Centre for Communication Technology, University of Malta, Msida MSD06. Malta (E-mail: albert.caruana@um.edu.mt).

The anthor wishes w thank Saviour Chicop and Willie Phua who helped in the collection of the data in Maln and Singaporc. respectively.

Journal of Euromarkeling, Vol. 14(4) 2005

Available online a hep:/www huworthpress.com/weh/JEM

(C) 2005 by The Haworth Press, be. All righs reserved.

doi: $10.13010 / 5037 \times 14004+05$ 
KEYWORDS. Anomia, ethnocentrism, microstates, small businesses

\section{INTRODUCTION}

Globalisation is arguably the major trend affecting the world. It can generate economic benefits as it integrates the advances in technology fostering efficiency and productivity in open unregulated markets. This process of globalisation is supported by the rapid growth of Free Trade Areas such as NAFTA, ASEAN and CARICOM together with consolidation of markets in European countries with the unfolding expansion of the EU, as well as large emerging markets in China and South America. The demise of communism, the emergence of a unipolar world, and the increasing adoption of free market systems by many developing countries further sustain it. Indeed, globalisation and the related liberalisation of markets has been the rallying call by major world institutions to developing countries as a panacea for economic growth and wealth. This is not to say that globalisation is not without its downside since it can include fiercer competition in previously sheltered markets, closure of entities that cannot cope and the displacement of workers, as well as environmental and social problems.

Many countries that sought industrialisation after independence provided their local manufacturers with protection in the form of tariffs and quotas against imported goods. Malta and Singapore provide interesting examples. Malta, with a population 0.4 million in a land area of $300 \mathrm{~km}^{2}$, and Singapore, with a population of 2.7 million in a land area of $600 \mathrm{~km}^{2}$, are both strategically located at the crossroads of the Mediterranean and South East Asia, respectively. Given the size of their domestic market, much of local businesses catering for local needs are in effect small or micro-businesses. The two states also have similar recent historical experiences; both were British colonies, became independent in the mid-60s and faced with large population densities and very limited natural resources, have sought to industrialise rapidly. In Singapore, the government supports free trade and has been active in the removal of levies and trade barriers much earlier than in the case of Malta. Liberalisation in Malta has been spurred by the impact of globalisation as well as EU harmonisation with approaching membership in May 2004.

Globalisation and related liberalisation involve the removal of levies and other barriers that have been around for decades. It has meant the 
entry of new players into formerly protected local markets and changes in local consumer preferences. These changes inevitably fuel perceptions of vulnerability, especially among owners/managers of small businesses. This vulnerability stems from their limited financial capability, technology and technical know-how to compete with world-class global corporations for market share and positions. As small businesses see the old social order of business change before their eyes, a sense of normlessness or psychological anomia results. In reaction such businesses often call for delays in policy implementation and make cries for defending the local product. These are manifestations of what in the literature is known as ethnocentrism and represents a construct that is important in marketing. This construct is generally used to represent 'the beliefs held by consumers about the appropriateness, indeed morality, of purchasing foreign-made products' (Shimp and Sharma, 1987). While ethnocentrism is often considered from the perspective of consumers, it can also be usefully considered from the perspective of owners and managers of small businesses. Psychological anomia better defined as: 'the breakdown of the individual's sense of attachment to society' (c.f., MacIver, 1950; Srole, 1956) does not appear to have received much attention in the management literature, and its effect on ethnocentric tendencies does not appear to have been investigated.

This paper focuses on the reaction of small enterprise managers and owners in Malta and Singapore as they face, or come to terms with, globalisation and liberalisation. The main objective is to investigate the existence of anomia as an antecedent link to ethnocentrism among small business owners and managers in the two island microstates. The research has theoretical implications as anomia does not appear to have been investigated in its effect on ethnocentric tendencies in the management literature. It also has practical implications for policy development.

\section{ETHNOCENTRISM AND ITS ANTECEDENTS}

Ethnocentrism is a sociological concept first introduced by Sumner (1906) that refers to a tendency to regard the beliefs, standards and code of behaviour of one's own as superior to those found in other societies. Ethnocentrism often serves the socially useful function of encouraging cohesion and solidarity among group members (in-groups) but can also contribute to attitudes of superiority, intolerance, and even contempt for those with different customs and lifeways (out-groups) (Booth, 1979; 
Levine and Campbell, 1972; Wagley, 1993; Worchel and Cooper 1979). Shimp and Sharma (1987) focus on the economic form of ethnocentrism which they term "consumer ethnocentrism" and define it as "the beliefs held by consumers about the appropriateness, indeed morality, of purchasing foreign made products.' These authors developed an instrument, termed the CETSCALE (Consumers' Ethnocentric Tendencies), that sought to measure consumer disposition in purchasing American-made products versus those of other countries. Sharma, Shimp and Shin (1995) consider consumer ethnocentrism as a trait-like quality of an individual's personality that acts as an antecedent to 'attitudes toward importing products' but is itself not an attitude.

The management literature has sought to identify antecedents, moderators and consequences of consumer ethnocentrism. A number of socio-psychological antecedents to consumer ethnocentrism have been identified. Shimp and Sharma (1987) report a positive correlation with 'dogmatism.' While in a later study, Sharma, Shimp, and Shin (1995) report a positive correlation with 'patriotism,' 'conservative attitudes' and 'collectivist tendencies' and a negative correlation with 'openness to foreign cultures.' Balabanis et al. (2001) argue that the scale used by Sharma, Shimp and Shin (1995) to measure 'patriotism' is more akin to a measure of 'nationalism.' Using different measures, the authors report that consumer ethnocentrism in Turkey is fuelled by 'patriotism' and by 'nationalism' in the Czech Republic. Their results also show that 'internationalism' that was hypothesised to be negatively related to consumer ethnocentrism had no effect in either country.

Studies of the influence of demographic antecedents of consumer ethnocentrism in terms of gender, education, income and age have provided mixed results. In terms of gender, women are reported to have a more favourable evaluation of products coming from abroad than men (Dornoff, Tankertsley and White, 1974; Schooler, 1971; Shimp, Sharma and Shin, 1995), while other studies have found no effect (Anderson and Cunningham, 1972). Balabanis et al. (2001) who make use of regression analysis, report gender to have an effect in the Turkish but not in the Czech sample. Shimp, Sharma and Shin (1995) report that ethnocentric tendencies are negatively correlated with greater levels of education achievement and increasing levels of income. On the aspect of income, Balabanis et al. (2001) report a positive effect in the Czech but not in the Turkish sample. As to age, Shimp and Sharma (1987) find in their Carolinas study the effect of age varies by social class and only older working-class individuals manifest ethnocentric tendencies. Balabanis et al. (2001) report age to have an effect in the Turkish but not in the Czech sample. 
Wei-Na, Ji-Young and Se-Jin (2003) have recently re-examined previously identified antecedents (nationalism, patriotism and internationalism) in a post 9/11 US consumer climate, while concurrently the quest for identifying and understanding the role of other antecedents such as consumer animosity (Klein and Ettenson, 1999) continues. Sharma, Shimp and Shin (1995:35) concede that the antecedent variables considered in the ethnocentrism literature are not exhaustive. The terms anomie and anomia are often used to distinguish between anomie at the sociological level and anomia at the psychological level. The original work on anomie comes from sociology. Like ethnocentrism, anomia is rooted in inter-group relations. We proceed to explicate the anomia concept and build the conceptual framework underpinning its antecedent link to ethnocentrism.

\section{ANOMIA}

Etymologically, anomie comes from Greek and literally means 'the absence of law.' The word has been variously used throughout time (Orrú, 1987) but took sociological meaning toward the end of the nineteenth century through the work of Émile Durkheim who drew on the earlier work of a fellow philosopher Jean Marie Guyau. The anomie of Durkheim (1933), and later Robert K. Merton (1957), refers primarily to a state of society while the later anomia refers to an individual's state of mind (MacIver, 1950; Srole, 1956).

Durkheim was concerned with the need for order in society and was preoccupied with social change when this led to unclear rules of behaviour. He viewed morality as being of a social nature that exists externally to the individual and constrains personal behaviour. Society is seen as the source of morality where 'all rules of conduct whose transgressions are sanctioned are moral rules.' Durkheim used anomie to describe a condition of deregulation occurring in society. Rules on how people ought to behave with each other were breaking down, they did not know what to expect from one another and cohesion in society was being eroded. He felt that sudden change and the adjustments to life that this required led to dissatisfaction, conflict and deviance. For Durkheim, anomie is a state that results where norms are confused, unclear or not present. It describes any form of deregulation or lack of cohesion that society may suffer from.

Durkheim is critical of what he considered the ill-conceived cultural objectives of industrial societies, questioning the prevalent value system and its ability to sustain cohesion. He argues that the 'ends' them- 
selves are the problem, and society must provide space for people to challenge them if social progress is to be achieved. In contrast, later writings by American researchers (e.g., Merton, 1957; Srole, 1956) reflect acceptance of the basic cultural goals of society. Rather, the concern has been with the consolidation of industrial societies, and their focus is primarily on the problems of adaptation.

For Merton (1957) anomie arises because of "the disparity between culturally emphasized goals and socially inaccessible means to actualise them.' 'Goals' refer to what society's members should strive for while 'means' are the legally or morally accepted ways that individuals can attain goals. Merton was particularly concerned with the characteristics of American society with its disproportionate emphasis on cultural goals encapsulated in the American dream-wealth, respect, a good job and family and a house in the suburbs. This vision is supposedly achievable by everyone via hard work. Anyone that fails simply needs to work harder and be patient. The 'legitimate means' to achieve this is via society's institutions, primarily education and employment that in an ideally organized society these will be equally available to all. However, not everyone has equal access to these institutions. For Merton it is this culturally induced pressure to be successful and the unequal access to institutions that results in tension or strain and the ensuing anomie. As a consequence, the resultant strain raises the possibility that certain individuals and social groups engage in rule-breaking behaviour. Although Merton recognises that collective rebellion aimed at changing the system is one possible group reaction, he argues that reactions tend not to be collective but individualistic. He terms these individual adaptations: conformity, innovation, ritualism and retreatism.

MacIver (1950) shifts the emphasis of anomie in sociology, with its emphasis on a state of society, to psychological anomia characterised as 'the breakdown of the individual's sense of attachment to society.' Contrary to Merton, who argues that anomie arises exclusively from capitalistic competitiveness where "those who having lost their ethical goals . . . transfer this drive into extrinsic values to the pursuit of means instead of . . . ends, and particularly to the pursuit of power,' MacIver (1950) highlights two additional circumstances in society that have psychological effects. First, the issue of culture clash represented by "those who having lost ... any system of value ... having lost the compass that points their course into the future, abandon themselves to the present.' Secondly, rapid social change that results in 'those who have lost the ground on which they stood, the ground of their former values.' As a result, 'The anomic man has become spiritually sterile, responsive only to 
himself, responsible to no one. He derides the values of other men. His only faith is the philosophy of denial. He lives on the thin line of sensation between no future and no past' (Mizruchi, 1964:48).

Srole's (1956) psychological theory of anomia builds on the work of MacIver and suggests that anomie and anomia are mutually indicative of each other; their relationship is reciprocal. At a macro level, Srole's theory of anomia looks at social integration; it describes the individual's loss of values in the face of rapid social change that results in a person's lack of integration in modern social life. At a micro level, Srole viewed anomia as an individual's generalised perception of 'self-to-others distance' and 'self-to-others alienation.' Srole identifies five distinct elements of anomia that he operationalised into a five-item scale (see items 1 to 5 in the Appendix) that emphasise normlessness.

\section{ANOMIA AND ETHNOCENTRISM}

Sharma, Shimp, and Shin (1995) identify 'perceived product necessity' and 'economic threat' as moderating variables in the effect of consumer ethnocentrism on their 'attitude toward importing products.' We argue that the ethnocentric trait is not only relevant to consumers, but in circumstances of economic threat resulting from activities like globalisation and liberalisation, it is also relevant to managers of small businesses. Moreover, changed economic conditions result in an upsurge of normlessness or anomia that has a direct effect on the ethnocentrism of small business managers which manifests itself in lobbying for protection and calls for maintaining the status quo.

The management literature does not appear to have considered anomia as a possible important antecedent to ethnocentrism, particularly among managers. There is, however, support in the social psychology literature for such a link with Billiet, Eisinga and Scheepers (1996) reporting anomia (together with social cultural localism and authoritarianism) to be a predictor of ethnocentrism in a study conducted among populations in the Netherlands and Flanders. Similarly, Scheepers, Felling and Peters, (1992) using classic theory of the authoritarian personality, conclude that anomic feelings resulting from one's social conditions induce ethnocentrism that are mediated by authoritarianism or what Ray (1990) calls an 'old fashioned orientation.' Moreover, in the initial Springfield study conducted by Srole (1956), the hypothesis that anomia was related to negative attitude toward minorities (an out-group) was confirmed. On the basis of the above, we hypothesise that: 
H1: The higher the level of anomia among owners and/or managers of small businesses, the higher will be their ethnocentric tendencies.

\section{MEASURES AND SAMPLES}

To investigate the link between anomia and ethnocentrism, the conceptualisations and measures by Srole (1956) and Shimp and Sharma (1987) respectively are used. Srole's measure of anomia is considered to be the most widely used measure of anomia in the social sciences and has been used in the annual General Social Survey of US National Opinion Research. The original 5-item instrument was improved with the addition of a further four items (cf. Robinson and Shaver, 1973). Poresky, Atilano and Hawkins (1981) use longitudinal data to test for the internal stability of the Srole scale with the enlarged 9-item scale. Three-year test-retest correlations indicated higher reliability and stability for the 9-item scale. Perhaps more important are Dodder and Astle's (1980) findings that the 9-item anomia scale provides stronger correlations with 'virtually every variable' grouped under the three headings of Demographics, Satisfaction and Social Involvements; headings that together make up 31 variables that are traditionally associated with anomia. For example, those with higher levels of occupational prestige, higher levels of education, higher levels of income and more satisfactory finances are associated with less anomia. On the other hand, dogmatism that refers to the degree of flexibility of an individual's values has been identified as an antecedent variable and results in higher levels of anomia.

To measure ethnocentrism the 17-item CETSCALE was used. The CETSCALE has been widely used, and support for its reliability, validity (Netmeyer, Durvasula and Lichtenstein, 1991) and invariance properties (Steenkamp and Baumgartner, 1998) across different countries is available. Other classificatory and demographic data consisted of type of business, number of years in the business, whether the respondent was a manager or owner, the number of employees, age and gender. The final instrument consisted of the 9-item Srole scale and the 17-item CETSCALE together with five items capturing demographic data. Each item in the two scales was measured using 7-point scales anchored $1=$ 'strongly disagree' and $7=$ 'strongly agree.'

Data are collected from two samples, one in Malta and another in Singapore. Besides being island economies, both countries are island 
states that became independent from Britain in the mid 60s, and both started off with similar economies that were primarily geared to the needs of the British military base. Both countries are also bilingual speaking a native or main language and English as a second widely spoken language. In Malta, a convenience sample consisting of individuals attending courses targeting small enterprise owners/managers was used. Potential respondents were assured of complete anonymity and that all results will be aggregated. A total of 96 valid replies were obtained. In the Singaporean study 783 postal questionnaires were dispatched to a list of small companies compiled with the help of the Association of Small and Medium Enterprises. A covering letter assuring anonymity was included, and a self-addressed and stamped envelope was enclosed. By the cut-off date, three weeks later, a total of 130 valid replies representing an effective rate of $16.6 \%$ were obtained.

\section{ANALYSIS}

The mean and standard deviations of the items in the Srole and CETSCALE scales are shown in Appendix 1. In terms of demographics and other classificatory variables, in the Malta sample $81.3 \%$ were male, $52.1 \%$ of respondents were owners, and the mean age was 36.70 ( $\mathrm{sd}$ 8.38). In terms of the number of years with the firm, in the case of Maltese respondents this was 13.54 (sd 9.89) while in the case of Singaporean respondents this was 11.78 (sd 9.55). As to average number of employees, in the case of the Malta sample this was 15.93 (sd 17.40) while in the case of the Singapore sample this amounted to 39.38 (sd 41.31). The internal reliability and validity of the instrument was tested. Reliability tests showed that in both cases all item-to-total correlations exceeded the 0.35 level in the case of the Srole's scale and the 0.5 level in the case of the CETSCALE. The only exception was the first item in the Srole scale, used in the Malta sample, that provided an item-to-total correlation of 0.29 . However, given the extensive testing done with this instrument in previous studies, it was decided to keep this item. The overall coefficient alpha (Cronbach, 1951) for each of anomia and ethnocentrism provided values of $0.83,0.96$ and $0.87,0.93$ for Malta and Singapore respectively. These comfortably exceeded the 0.70 thresholds and are therefore acceptable (Nunnally, 1978). Principal components factor analysis followed by a varimax rotation was undertaken concurrently on the two scales to determine the dimensionality of the scale as well as its discriminant validity. The results shown in Ta- 
ble 1 confirm a clear factor structure with each of the two constructs loading separately in both samples.

The sum of the scales for ethnocentrism and anomia were computed. These were used in two separate regression equations first using the Malta and then Singapore data. In both equations, anomia and ethnocentrism were treated as the independent and dependent variable respectively. Results proved significant with both samples providing support for the hypothesis of this study. (Malta: $R^{2}=0.26$; F 33.56, $\mathrm{p}<0.00$; Std. $\beta=0.51, \mathrm{p}<0.00 ;$ Singapore: $R^{2}=0.05 ; \mathrm{F}=6.06, \mathrm{p}<0.05 ;$ Std. $\beta=$ $0.22, \mathrm{p}<0.05)$.

TABLE 1. Results of Principal Component Analysis with Varimax Rotation

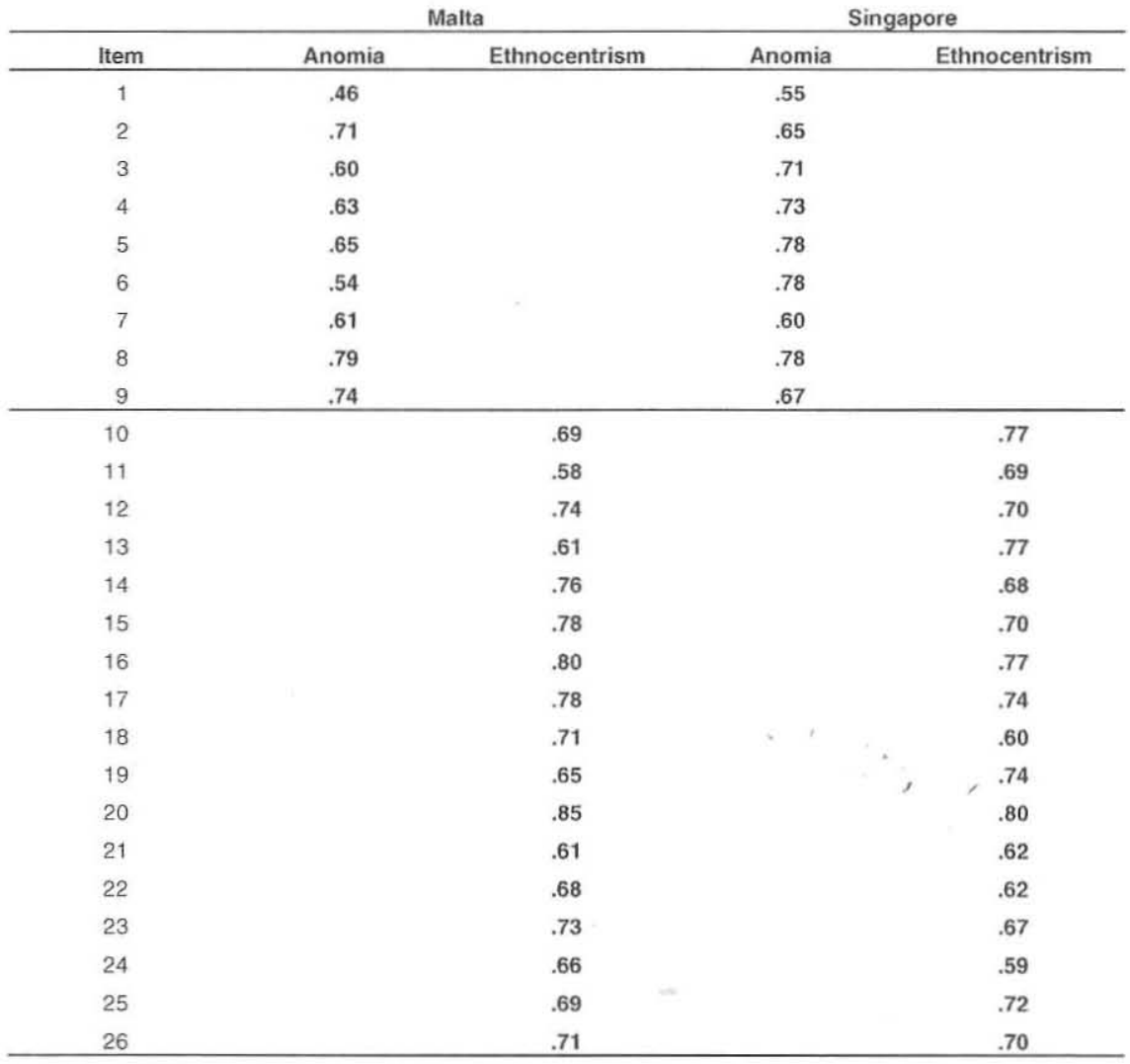

Vales less than 0.50 not shown, except for item 1 for the anomia scale in the Malta data. 
Comparison of means for the two constructs of anomia and ethnocentricism show that the Malta respondents exhibit higher levels of ethnocentrism $(\mathrm{t}=-3.03 ; \mathrm{p}<0.00)$ but equivalent levels of anomiaTable 2a. Further analysis of the two constructs was undertaken to investigate how these varied with the classificatory and demographic variables collected. In the Malta sample, age of respondent was negatively correlated to anomia $(r=0.23: \mathrm{p}<0.01)$ while employee managers exhibited higher levels of anomia than owner respondents $\left(\chi^{2}=\right.$ $10.93 ; \mathrm{p}<0.01)$. Also, respondents that have been in an industry for 10 years or less exhibit higher levels of anomie-Table $2 b$-while analysis of ethnocentrism scores by type of industry showed higher levels among the furniture and printing sectors-Table $2 \mathrm{c}$. In the Singaporean sample, the demographics collected indicated no statistically significant relationships with the two constructs in the study.

\section{DISCUSSION}

The main objective of this study was to investigate the possible existence of a link between anomia and ethnocentric tendencies among owners/managers of small businesses. The results from both Malta and

TABLE 2a. Differences in Means for Ethnocentrism and Anomie by Country

\begin{tabular}{|c|c|c|c|c|c|c|}
\hline & Country & $\mathrm{N}$ & Mean & $\begin{array}{c}\text { Std. } \\
\text { Deviation }\end{array}$ & $\mathrm{t}$ & Sig \\
\hline \multirow[t]{2}{*}{ Ethnocentrism } & Singapore & 122 & 45.30 & 15.95 & -3.03 & 0.00 \\
\hline & Malta & 96 & 53.56 & 22.66 & & \\
\hline \multirow[t]{2}{*}{ Anomia } & Singapore & 122 & 37.85 & 7.83 & -1.27 & 0.21 \\
\hline & Malta & 96 & 39.50 & 10.70 & & \\
\hline
\end{tabular}

TABLE 2b. Malta Sample: Differences in Means for Ethnocentrism and Anomie by Years with a Company

\begin{tabular}{|c|c|c|c|c|c|c|}
\hline & Type & $\mathrm{N}$ & Mean & $\begin{array}{c}\text { Std. } \\
\text { Deviation }\end{array}$ & $t$ & Sig \\
\hline \multirow[t]{2}{*}{ Ethnocentrism } & 10 years and less & 46 & 52.38 & 23.81 & -0.23 & 0.82 \\
\hline & Mure than 10 years & 46 & 53.49 & 22.12 & & \\
\hline \multirow[t]{2}{*}{ Anomia } & 10 years and less & 46 & 42.02 & 10.25 & & \\
\hline & More than 10 & 46 & 36,46 & 10.36 & 2.59 & 0.01 \\
\hline
\end{tabular}


TABLE 2c. Malta Sample: Differences in Means for Ethnocentrism and Anomie by Type of Industry

\begin{tabular}{llrrrrr} 
& \multicolumn{1}{c}{ Type } & N & Mean & $\begin{array}{c}\text { Std. } \\
\text { Deviation }\end{array}$ & 1 & Sig \\
\hline \multirow{2}{*}{ Ethnocentrism } & Fumiture/printing & 44 & 59.85 & 21.38 & & \\
& Others & 52 & 48.23 & 22.53 & 2.58 & 0.01 \\
\hline \multirow{2}{*}{ Anomia } & Furniture/printing & 44 & 41.43 & 8.66 & & \\
& Others & 52 & 37.87 & 12.00 & 1.69 & 0.10
\end{tabular}

Singapore provide support for this hypothesis. The findings provide an important theoretical contribution as it extends to management the findings observed in social psychology where anomie is known to be an antecedent to ethnocentrism. It suggests that anomia can be included as an important additional antecedent to ethnocentrism, thereby suggesting the extension of the basic model provided by Sharma, Shimp and Shin (1995). This is in line with the call made by these authors who encourage investigation of other antecedents to ethnocentrism.

The research also sheds some light on the situation prevailing in Malta and Singapore among small business owners/managers. The results of the two regressions show that anomia is a statistically significant antecedent in both countries, but the relationship is stronger in Malta than in Singapore. This indicates that the effect of anomia on ethnocentrism is possibly being mediated by way of another variable or variables. In absolute terms, the scores obtained for anomia in the two countries are not statistically different, yet the level of ethnocentrism is statistically higher among respondents in Malta. In certain sectors, liberalisation in Malta is a more recent happening and sub-analysis of the Malta sample indicates that the more recently liberalised furniture and printing sectors do exhibit higher levels of ethnocentrism.

Anomie results from changes in the accepted economic or social goals held by the culture to which individuals belong. In the context of this study, changes in economic goals arising from activities like the liberalisation of home markets in turn result in higher levels of ethnocentrism among owner/managers. High levels of managerial ethnocentrism among these owner/managers are likely to present a formidable mental barrier to the adoption of an alternative strategy or strategies that can meet the new reality. For example, owner/managers of recently liberalised markets previously benefited from protection through import restrictions and were able to meet local demand via local manufacturing. The new goals that liberalisation brings along engender higher levels of ethnocentrism that 
can impede the timely adoption of alternative strategies such as moving to an importation strategy to meet the same market need.

Small business managers' hostility toward liberalisation of imports will be reflected in strong lobbying and campaigning by representative organisations. Changing the attitudes of small business managers toward liberalisation of import restrictions requires mitigation of their ethnocentrism. Therefore, an improved understanding of the mediating interactions among the antecedent variables of ethnocentrism could enable agencies charged with implementing liberalisation policies to implement better economic policies. As the situation stands, such agencies are often acting in the dark and launch support schemes and communication activities that may have little or no real impact which often tackles the effect in terms of outcry rather than the cause. Once the key drivers to ethnocentrism and disposition toward liberalisation of imports are identified, they can be monitored via regular market research.

Like any research, this study has its limitations. First, since it only looks at two variables, it does not look at potential moderating or mediating variables in the link between anomia and ethnocentrism. Second, while the reliability and factor structure of the scales obtained are robust and there is evidence of cross-national invariance for the CETSCALE and evidence of the use of Srole scale across countries, the degree of adaptation of the scales to the circumstances of managers, rather than of consumers, needs further consideration. Thirdly, there are limitations with respect to the Malta sample in particular, since it is essentially a convenience sample.

In investigations of ethnocentrism, the focus in the management literature has been on consumer ethnocentrism. This research extends the application of ethnocentrism beyond consumers to owners/managers in small businesses. It raises the possibility of extending this even further to managers in larger organisations and to other stakeholders. Management ethnocentrism is very likely to influence the strategic alternatives and choices that management makes. It, therefore, opens a whole new area of possible research investigation.

Transferring constructs and theories developed for larger markets and testing these in smaller micro-markets is to be encouraged as it strengthens the wider application of theory that very often has a large market focus. Conversely, the link between anomia and ethnocentric tendencies among owners/managers of small businesses that has been supported in these two micro-markets needs to be tested in larger markets. Such an approach can considerably strengthen the detailed model of ethnocentrism that is emerging in the management literature, ensuring its widest possible generalisability. 


\section{REFERENCES}

Anderson W. T., and Cunningham W. H. (1972). Gauging foreign product promotion, Journal of Advertising Research, 12(1), February, 29-34.

Balabanis G., Diamantopoulos A., Mueller R. D., and Melewar T. C., (2001). The impact of nationalism, patriotism and internationalism on consumer ethnocentric tendencies, Journal of International Business Studies, 32(1), 157-175.

Billiet J., Eisinga R., and Scheepers P., (1996). Ethnocentrism in the Low Countries: A Comparative Perspective, New Community, 22(3), 401-416.

Booth K., (1979). Strategy and Ethnocentrism, London: Croom Helm.

Cronbach, L. J. (1951). Coefficient alpha and the internal structure of tests, Psychometrika, 16 (3), 297-333.

Dodder R. A. and Astle D. J. (1980). A methodological analysis of Srole's nine-item anomia scale. Multivariate Behavior Research, 15, 329-334.

Dornoff R. J., Tankertsley C. B., and White G. P., (1974). Consumers' perceptions of imports, Arkon Business and Economic Review, 5(Summer), 26-29.

Durkheim E. (1933). The Division of Labor; (G Simpson, Trans.), New York: Free Press. (Original work published 1893).

Klein, J. G., and Ettenson R., (1999). Consumer Animosity and Consumer Ethnocentrism: An Analysis of Unique Antecedents Joumal of International Consumer Marketing, 11(4) 5-24.

Levine R., and Campbell D. T., (1972). Ethnocentrism: Theories of conflict, ethnic attitudes, and group behavior, New York: John Wiley.

MacIver R. M., (1950). The Ramparts We Guard. New York: Macmillan.

Merton R. K., (1957). Social structure and Anomie. American Sociological Review, 3(June), 672-682.

Mizruchi E., (1964). Success and Opportunity: A Study of Anomie. New York: The Free Press.

Netemeyer R. G., Durvasula S., and Lichtenstein D. R., (1991). A cross-national assessment of the reliability and validity of the CETSCALE, Journal of Marketing Research, XXVII (August), 320-327.

Nunnally, J. C., (1978). Psychometric Theory (2nd. ed.). New York: McGraw Hill.

Orrù, M. (1987). Anomie. Winchester, MA: Allen \& Unwin Inc.

Poresky R. H., Atilano R. B., and Hawkins K., (1981). Anomia in rural women: A longitudinal comparison of two measures, Psychological Reports, 49, 480-482.

Ray J. J., (1990). The old fashioned personality, Human Relations, 43, 997-1015.

Robinson, J. P. and Shaver, P. R., (1973). Measures of Social Psychological Attitudes. Ann Arbor, MI: University of Michigan, Survey Research Center.

Scheepers P., Felling A. and Peters J., (1992). Anomie, authoritarianism and ethnocentrism, Poliics and the Individual, 2, 43-60.

Schooler R. D., (1971). Bias phenomena attendant to the marketing of foreign goods in the US, Journal of International Business Studies, Spring, 71-80.

Sharma S., Shimp T. A., and Shin J., (1995). Consumer ethnocentrism: A test of antecedents and moderators, Journal of the Academy of Marketing Science, 23(1), 26-37. 
Shimp T. A., and Sharma S., (1987). Consumer Ethnocentrism Validation of the CETSCALE Construction and Validation of the CETSCALE, Journal of Marketing Research, VVIV(August), 280-289.

Srole L., (1956). Social integration and certain corollaries: An exploratory study. American Social Review, 21 (December), 709-716.

Steenkamp J-B, and Baumgartner H., (1998). Assessing measurement Invariance in cross-national consumer research, Journal of Consumer Research, 25(June), 78-90.

Sumner G. A., (1906). Folkways, New York: Ginn Custom Pub.

Wagley C., (1993). Ethnocentrism, New York: Grolier Pub.

Wei-Na L., Ji-Young H., and Se-Jin L., (2003). Communicating with American consumers in the post $9 / 11$ climate: an empirical investigation of consumer ethnocentrism in the United States International Journal of Advertising, 22(4) 487-500.

Worchel S., and Cooper J., (1979). Understanding Social Psychology, Homewood, IL: Dorsey Press.

Received: February 2004 First Revision: October 2004 Second Revision: November 2004 Accepted: February 2005 